\title{
DESENTRAÑANDO EL COMENTARIO DE CIPRIANO DE LA HUERGA AL SALMO $130^{*}$
}

\author{
N. FERNÁNDEZ MARCOS \\ EMILIA FERNÁNDEZ TEJERO \\ CSIC. Madrid
}

Existen dos ediciones latinas del comentario de Cipriano de la Huerga al Salmo 130:

1. Cypriani Huaergensis... in Psalmum 130 commentarius, Lovanii, Apud Hugonem Cornwelem Typogr. Iurat. Anno Domini M.D.L. Mense Martio (en adelante, 1550);

2. Cypriani Monachi Cisterciensis... Commentarius in Psalmum CXXX, Complvti, Ex officini Ioannis Brocarij 1555.

Contamos también con dos manuscritos castellanos:

1. Ms 26.III.10 (siglo XVI), fols. $1 \mathrm{r}-115 \mathrm{v}$ del Instituto «Valencia de Don Juan", Madrid (en adelante, VJ);

2. Coimbra BGU 92, 84 fols., siglo XVI (en adelante, Coimbra). Esta copia se inicia con una dedicatoria «Al excelentissimo señor Don Fernando Alvarez de Toledo Duque de Alba Marques de Coria Maiordomo mayor de su Magestad y del consejo de estado", que firma el traductor, Don Bernardino de Mendoça. Esta dedicatoria falta en la copia de VJ que también carece del conocido ex libris de Cipriano de la Huerga. El ex libris sí aparece, reproducido a mano, en la primera página del manuscrito de Coimbra, con traducción castellana del texto hebreo: «El Señor abrio a mi la oreja y yo no traspasse del mandado" (Is 50,5), y del griego: "A Cristo".

Las dos ediciones latinas llevan la misma aprobación, fechada en Lovaina, el 19 de enero de 1549 . Nos encontramos, sin embargo,

* Para una primera aproximación al autor y su obra cf. nuestro artículo «El ex libris de Cipriano de la Huerga», Sefarad LII (1992) 85-96

1 Visum et admissum per Petrum Curtium Pastorem Diui Petri Louanien. tanguam nihil habens quod fidei aut religioni Christianae aduersetur (aduersatur en la edición de Lovaina). Die. 19. Ianuarii. Anno. 1549. Stilo Braban., que traducen así los manuscritos castellanos: «Visto y aprouado por Pedro Curcio cura de la yglesia de San Pedro de Louayna por no hauer nada que contradiga a la fe y religion Cristiana hecha a 19 de Enero 1549 por el estilo y orden de Brabante». 
ante ediciones diferentes: la de 1555 es bastante más amplia que la de 1550; difieren también tipográficamente: la de 1550 carece de hebreo en el texto; sin embargo, incluye al final un apéndice de cuatro folios en los que se comentan algunas expresiones hebreas de los versículos 2-7. La de 1555 incluye los comentarios hebreos a lo largo de la obra y carece de apéndice.

Quizá la edición de Alcalá de 1555 fuera necesaria por los muchos errores que contenía la de Lovaina de 1550, a los que alude Pedro de Fuentidueñas en el fol. $7 \mathrm{v}$ de la epístola al lector cristiano que encabeza la edición del comentario de Cipriano de la Huerga al Salmo 38 (Alcalá 1555) donde se lee

Adiecimus etiam in tuam gratiam, commentaria in Psalmum 130 olim Louanij excussa, sed multis erroribus deprauata».

En cuanto a la traducción castellana (VJ y Coimbra) está hecha sobre la edición de 1555 , como puede constatarse no sólo a la vista de la disposición del hebreo sino también por su contenido. Un simple cotejo de los textos latinos con la traducción castellana permite llegar a esta conclusión.

El objeto de este artículo es analizar el tratamiento dado a los pasajes hebreos en las dos ediciones latinas. Incluimos en primer lugar una reproducción y traducción del apéndice de la edición de 1550, para compararlo después con el texto de la edición de 1555 . Vaya por delante la apreciación obtenida de un sondeo de ambas ediciones: la de 1555 corrige, modifica - sobre todo estilísticamentea veces condensa y, en general, amplía la de 1550. Se trata, por tanto, de dos redacciones distintas.
REPRODUCCIÓN DEL APÉNDICE DE LA EDICIÓN DE LOVAINA (1550)

\section{Asts}

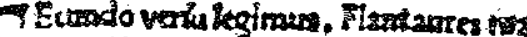

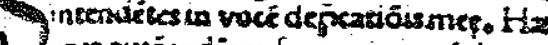
L Jrea auté vidétar forkers in yocé depra

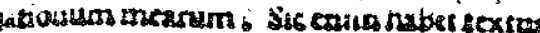

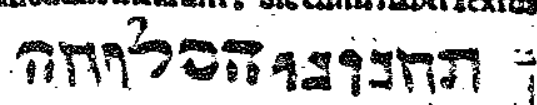

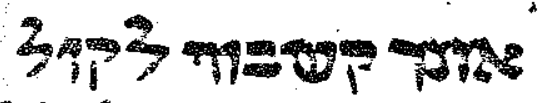

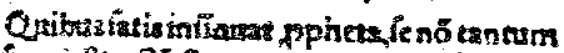

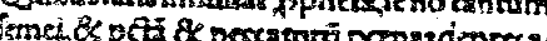

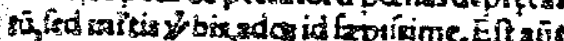
政

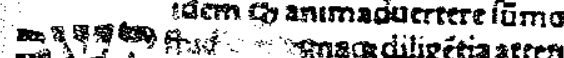

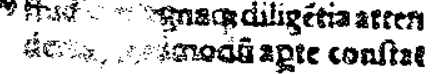
rehimense - Quolococadé 119.

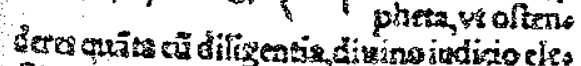

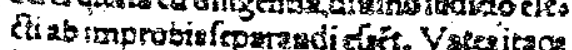

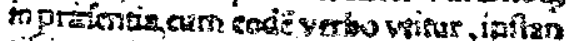

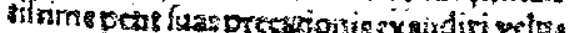

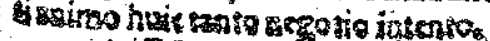

17)

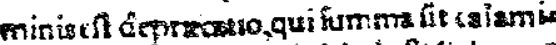
sace,infisntiva pericuio. V'nde Q Salomon

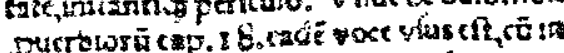
quir Fuper cusm oblecristonibos luquitus, quit,

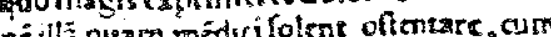
quidoiam effagitart contendurt.

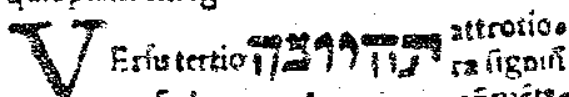
cet ícelera quad parim in cóniérs

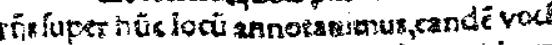

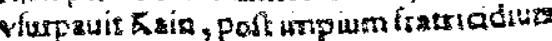

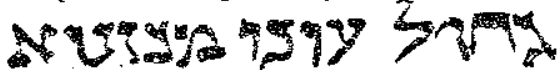

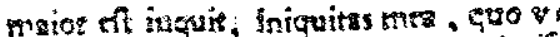

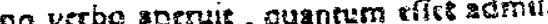
ipecesi pordis, abeamque conlam cuod I1pecatip

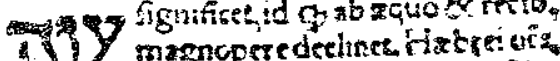
imno liter fact

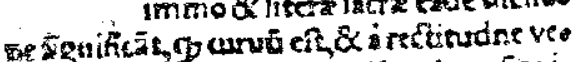

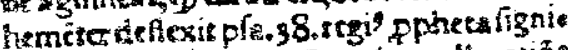

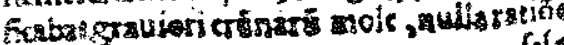


$+$

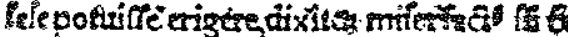
- hoc iftincertrats inim 117 Hacidco annokaimu r to : quoptoletorichender

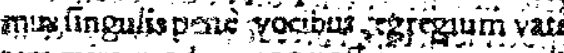

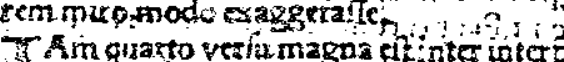
Thin quarto vefa magna elinte uta

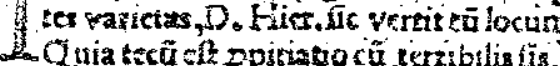

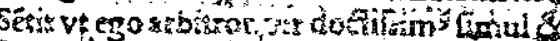

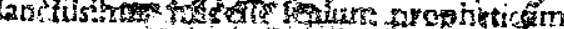

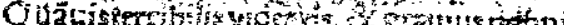
Q Q

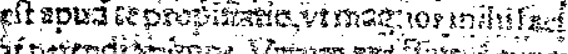

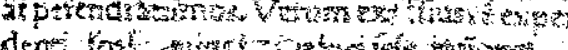

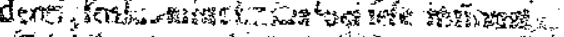

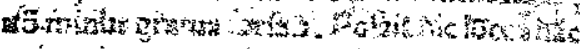

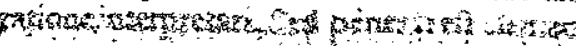

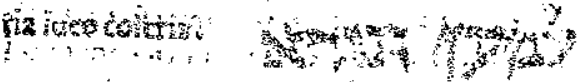

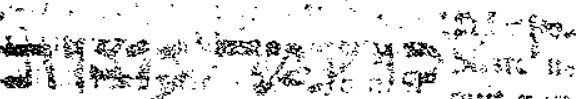
-

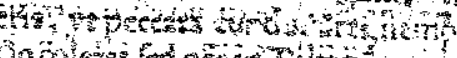

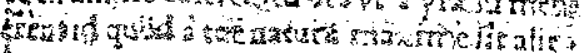

4 num. Is lenius mithi videtur maxime of be

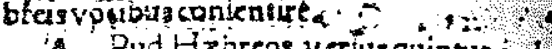
1. Pud $\mathrm{H} x$ recos verius quintus inde 1.7. incipit Suftinur deminũ expectalu $\alpha$ anima mea $\&$ in verbo eius fidust habeo. Ad eü fetme modü, D. Hieronimu iegit, \& inecrpretatur hü locu, Suftinuit a gingentita

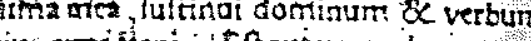
cis exptctaut. 'Ets autem verbum. quo vates vtrobig vius ent, nöt Af 2 lú fuftinere, verü etiż $\alpha$ anmo Tare. Vurur alias code verbo fepifime in masnis peritulisprátensaliquod tom

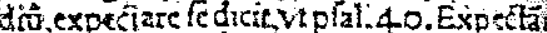

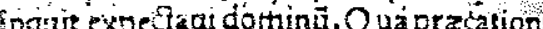
mantexpent ange

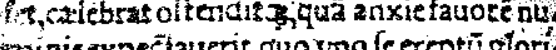
ktanis expectauerit quo vno fe ercptü glorio

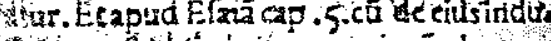

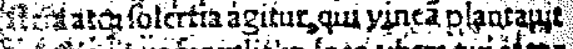

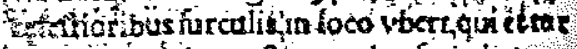

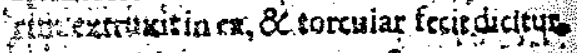
1) और n
6. "3

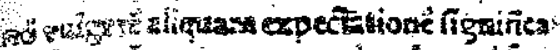

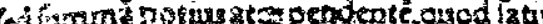
un

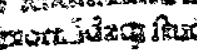

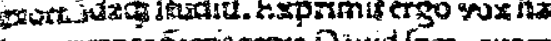

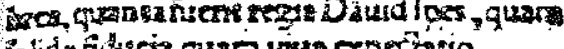

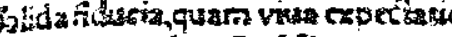

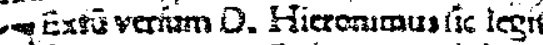
- isintererstatur. Aninis mes ad dom murmà vigilia matution vía ać vigitis

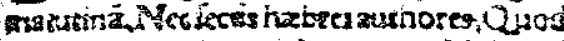

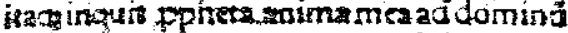

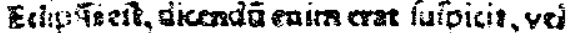

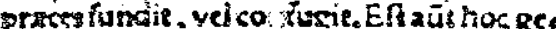

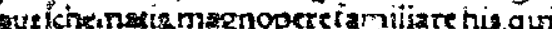
a ardé

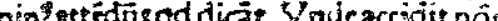
mine (1) - 1 or - of anteruá custodes

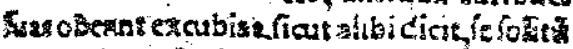

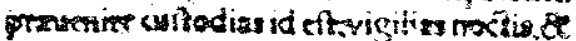

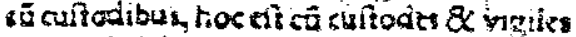

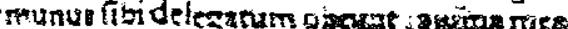
Geis atrailit $0 \mathrm{cum}$.

Sotions

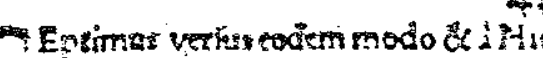
rorytno; Z sb hebrets eurthoribus pug - Tarar. Spare? itrzel in Domino, suiv

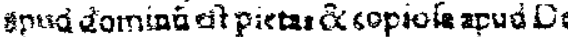

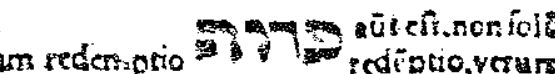
edéptio,verur

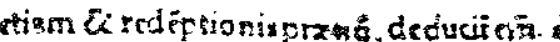
aucd verbus $\&$ liberale 28 eruepe

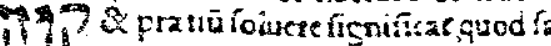
is conerait in exinuü benericium redemptionis a Chrifto in nos coliatu. N gue enimrenifsionem ícelerum dum

is rastuito noftro negurio sosis \& rangunis preftio oscohic. mit ve Prtus cort:

ăfignerituius pialnilos:

- Cam deum prectmup, noftre conuito

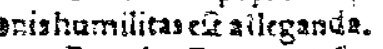

- Crander Deus nenotiroram operesa estionem habese, fed luspotius bontasia in *raesertulg.

\section{a} as $\quad \therefore$ 
TRADUCCIÓN ${ }^{2}$

[2] En el versículo segundo leemos Fiant aures tuae intendentes in vocem deprecationis meae. Sin embargo, el hebreo parece decir in vocem deprecationum mearum. Pues así es el texto:

$\therefore$

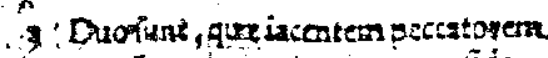

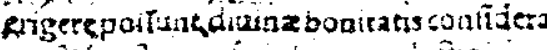

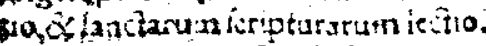

4 Cum vota nolisa differuatur, cone? ab orationeceitandum.

5 Magnam foeméa it peceatori, in eo

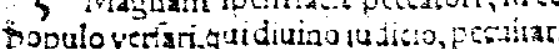
rationentelecilus :

\section{Amotationum finis,}

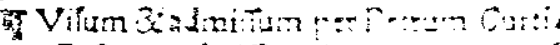

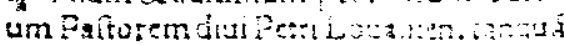

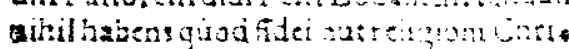

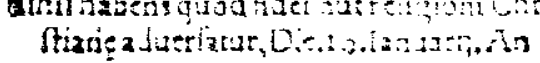

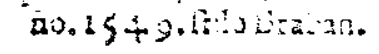

\section{LOVANI:}

gone

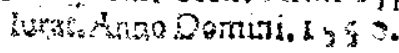

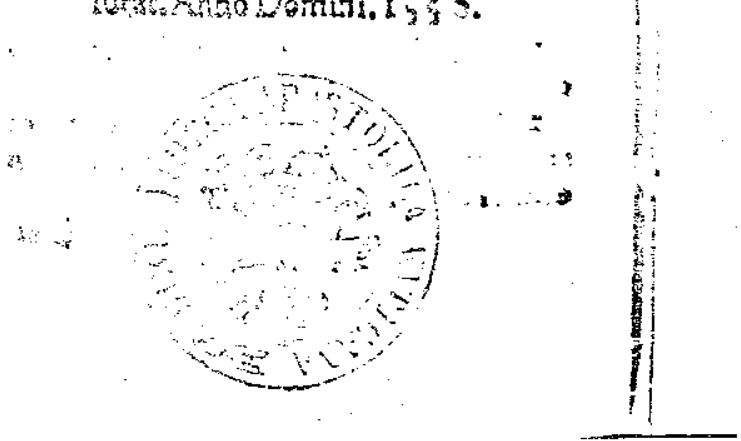

\section{תחנוני הסליחה \\ אזנך קשבות לקול הסיחר}

Con lo cual el profeta sugiere claramente que no ha suplicado sólo una vez por el pecado y por los castigos de los pecadores, sino con muchas palabras y muchas veces. Porque קשב significa advertir con gran cuidado y considerar con mucha diligencia, como claramente consta por el testimonio de Malaquías, capítulo 3, [16]:

\section{וישמע ויקשב יהוה}

En este lugar utilizó la misma palabra el profeta, para mostrar con cuánta diligencia habrán de ser separados de los réprobos los elegidos por voluntad divina. De esta forma, el profeta, en ese pasaje, a utilizar la misma palabra, pide con insistencia que sus súplicas sean oídas, como si tuviese el ánimo pendiente tan sólo de este asunto tan importante.

תo es tanto oración cuanto ruego suplicante y en definitiva es la súplica de un hombre que está en gran calamidad y peligro inminente. Y así Salomón en el capítulo 18,[23] de los Proverbios utilizó la misma palabra cuando dice «El pobre habla con plegarias» para expresar mejor el dolor y la ansiedad que suelen mostrar los mendigos cuando se esfuerzan por conseguir algo.

En el versículo tercero תהיינה significa crímenes atroces, que ya en parte hemos anotado en el comentario precedente; la misma palabra utilizó Caín después del impío fratricidio

$$
\text { גדול עוני מִנמשא.' }
$$

«enorme es -dijo- mi iniquidad». Con esta sola palabra demostró cuán grande era el peso del pecado cometido, e igualmente lo que

${ }^{2}$ En la traducción de este apéndice se ha respetado la forma del hebreo tal y como aparece en el comentario de Cipriano de la Huerga, aun en los casos de error vidente. Las correcciones se incluyen en el comentario que le sigue.

${ }^{3}$ Gen 4,13 
significa עוה, a saber, lo que mucho se aparta de lo justo y recto. Más aún, todos los hebreos y las Escrituras Sagradas indican con la misma expresión lo que es curvo y se aparta en demasía de la rectitud. En el Salmo 38,[7] el profeta regio indicaba que no se podía enderezar en absoluto, por la abrumadora carga de tribulaciones y dijo "He sido hecho miserable», נעויתי, es decir, "estoy encorvadom. Hemos anotado todo esto para mostrar al piadoso lector que el profeta egregio puso énfasis de manera admirable en casi cada una de las palabras.

En el versículo cuarto hay gran discrepancia entre los intérpretes. El divino Jerónimo traduce así el pasaje: Quia tecum est propitiatio cum terribilis sis. En mi opinión, cree este hombre sapientísimo a la vez que santísimo que se trata de un sentido profético: aunque parezcas terrible y en ocasiones reprendas duramente a los pecadores, sin embargo, tanta es tu misericordia que me das gran aliento para implorar. Pero a quien esto sopesa más detenidamente, se le manifiesta otro sentido de este pasaje no menos gratificante. Pues este pasaje pudiera interpretarse del siguiente tenor: «Mas en ti está la clemencia y por eso se te venera»,

\section{למען תורא כי עמך עונות}

Si no fueras conocido por aquella benignidad - dijo- que perdona los pecados, nadie te veneraría de corazón, sino que todos te temerían como a un tirano, que es lo más opuesto a tu naturaleza. Este sentido me parece que concuerda de maravilla con las palabras hebreas.

En hebreo el versículo quinto empieza: «Esperé en el Señor, esperó mi alma, y en su palabra tengo confianza». Casi de la misma manera lee e interpreta este pasaje el divino Jerónimo: Sustinuit anima mea, suistinui dominum et verbum eius expectaui. La palabra פד, que usa el profeta en ambos lugares, no sólo significa sostener, sino también esperar alguna cosa con ánimo ansioso y anhelante. Usa con mucha frecuencia la misma palabra en otros pasajes, cuando al encontrarse inmerso en grandes peligros dice que espera algún remedio, como en el Salmo 40,[2]: «Esperando -dijo- esperé al Señor», Con esta súplica declara y expresa alguna calamidad grand por la que estaba afligido y con cuánta ansiedad esperaba el favor de la divinidad, por el solo cual favor se precia de haber podido enderezarse. Y en Isaías capítulo 5,[2], cuando se trata del trabajo y el ingenio del quèe plantó la viña con excelentes vástagos, en lugar fértil , que edificó una torre en ella e hizo un lagar; dice:

\section{ויקו לעשות ענבים}

esto es, «esperé que diera uvas, pero dio agrazones». En este pasaje el verbo קוה no indica una esperanza cualquiera, sino la mayor y más anhelante, lo que de sobra pone de manifiesto tamaña dedicación en plantar, cavar y cuidar la viña. Expresa, pues, la palabra hebrea cuán grande fue la esperanza del rey David, cuán sólida su confianza, cuán vivo su anhelo.

El divino Jerónimo lee e interpreta así el sexto versículo: Anima mea ad dominum, a vigilia matutina, usque ad vigiliam matutinam, y no de otro modo los autores hebreos. Pues así dijo el profeta: «mi alma al Señor». Es una elipsis, pues habría de decirse «se vuelve», O «profiere súplicas», o «se acoge». Este tipo de figura es muy familiar a aquellos que deseando o pidiendo algo con ardor, prestan poca atención a lo que dicen, de donde sucede a veces que les falta alguna palabra o se les escapa. Y משמרים puede interpretarse no sólo «antes que los centinelas», es decir, antes de que los centinelas hagan sus guardias -y así lo dice en otro pasaje, que él está acostumbrado a anticiparse a las guardias ${ }^{4}$, es decir, a las vigilias de la noche- - sino "con los centinelas"; es decir, cuando los centinelas y guardias cumplen la tarea que se les ha encomendado, «mi alma se eleva a Dios».

El versículo séptimo es leído de igual forma por Jerónimo y por los autores hebreos. «Espere Israel en el Señor, porque en el Señor hay bondad y en Dios hay abundante redención". פדות es no sólo redención, sino también el precio de la redención; se deduce de que esta palabra significa librar, arrancar y pagar un precio, lo que concuerda con el excelente favor de la redención que nos trajo Cristo. Porque no nos regaló la remisión de los crímenes por ningún esfuerzo nuestro, sino que nos compró por el alto precio de su sangre, como enseña Pedro s.

\footnotetext{
${ }^{4}$ Cf. Ps 118,148 .

${ }^{5}$ Cf. 1 Pe 1,19
} 
Pasajes notables de este salmo

1 Cuando oramos a Dios hay que alegar la humildad de nuestra condición. 2 Hay que pedir a Dios que no tenga en cuenta nuestras obras, sino más bien su bondad derramada a todos.

3 Dos cosas hay que pueden enderezar al pecador postrado, la consideración de la divina bondad y la lectura de las Sagradas Escrituras.

4 Cuando nuestros deseos tardan en cumplirse, no hay que dejar de orar.

5 Da una gran esperanza al pecador tener presente a aquel pueblo que fuera elegido por voluntad divina y por una razón particular.

Fin de las anotaciones

\section{COMENTARIO} 1555 .

Veamos ahora cómo figuran estos pasajes en la redacción de

El párrafo correspondiente al versículo segundo se encuentra en los fols. 34b-36a de la edición de 1555. Se inicia con la frase Sic sane Hebraea sonare videntur, y el latín que da como lema difiere ligeramente del latín del apéndice:

- 1550: Fiant aures tuae intendentes in vocem deprecationis meae.

- 1555: Fiant aures tuae intentissimae in vocem deprecationum mearum.

El hebreo es correcto en la edición de 1555, frente a las erratas que se deslizaron en la de 1550: la segunda línea debe preceder a la primera, y la palabra הסליחה pertenece al versículo cuarto; también en la cita de Malaquías que le sigue está invertido el orden de las palabras hebreas. Con toda seguridad estas erratas se debieron a un impresor no muy avezado en el hebreo, puesto que el comentario de Cipriano de la Huerga se ajusta al texto que cabría esperar. El texto latino es el de 1550, con variantes (sinónimos, ądición u omisión de alguna frase explicativa). En cuanto a la traducción castellana, el manuscrito de Coimbra incluye la transcripción del hebreo - transcripción que no está en VJ- y en la cita de Proverbios 18,23 (fol. 36b) traduce correctamente el latín pauper (fol. 35b), como 'pobre', frente al 'hombre' de VJ (fol. 45a).

El párrafo correspondiente al versículo tercero se encuentra en los fols. 41a-41b en la edición de 1555. Faltan las tres primeras líneas del texto latino del apéndice en las que, precisamente, hay una errata en el lema del hebreo: en vez de עונות, dice תהיינה, que pertenece al versículo anterior $y$, naturalmente, nada tiene que ver con el comentario. Los demás lemas hebreos del comentario al versículo tercero son correctos en el apéndice. El texto latino se mantiene, con variantes. En cuanto a la traducción castellana, la de Coimbra transcribe también el hebreo; aquí parece ser más ajustada al latín la traducción de VJ (fol. 52b): «mayor es mi maldad que se pueda llevar» que la de Coimbra (fol. 42a) «Mayor es mi maldad que se puede llevar», para el latín Maior est iniquitas mea, quam ut leuari possit (fol. 41a); «el mesmo Real Propheta» (VJ, fol. 53a), «el mesmo Rey propheta» (Coimbra, fol. 42a) para el latín idem Regius propheta (fol. 4lb)

El párrafo correspondiente al versículo cuarto se encuentra en los fols. 59a-59b de la edición de 1555. En la edición de 1550 el lema hebreo es incorreto: למען תורא precede a כי עמך que va seguido de עונות la palabra que se esperaría en vez de comentario al versículo anterior. El latín difiere por completo en ambas ediciones; tan sólo puede rastrearse como punto de contacto la alusión final al tirano. Además, la traducción del lema hebreo en la edición de 1555 (fol. 59b) es parafrástica: Quia tecum misericordia est, propterea tibi timorem et venerationem mortales tribuunt, y no se identifica con ninguna de las dadas en el pasaje correspondiente del apéndice. Los textos castellanos coinciden totalmente; el hebreo se encuentra también transcrito en la edición de Coimbra.

El párrafo correspondiente al versículo quinto se encuentra en los fols. 66b-67b de la edición de 1555 . El lema hebreo del apéndice es erróneo: קוה : El primer párrafo latino falta en la edición de 1555; en él Cipriano de la Huerga traduce muy literalmente el texto hebreo, apartándose de LXX y de Vulgata; se respeta, además, el sistema hebreo de acentuación, pues, como pide el acento disyuntivo 'atnah, in verbo eius depende de fiducia habeo, no de expectauit anima mea. El resto del texto latino es prácticamente el mismo, con alguna variante. Los textos castellanos coinciden totalmente; el manuscrito de Coimbra transcribe el hebreo, como de costumbre.

En los fols. $68 \mathrm{a}-68 \mathrm{~b}$ de la edición de 1555 se incluye un comentario sobre la palabra נפ -también del versículo quinto- que falta en el apéndice. Los textos castellanos coinciden, excepto en los 
puntos siguientes: «acerca de los Hebreos» $\mathrm{y}$ «significar el alma a lo menos aquella virtud» (VJ, fol. 88a); «acerca de los hombres» y «significar aquella virtud» (Coimbra, fol. 65b). El primer manuscrito reproduce el latín de manera más literal: Hebraice y vel saltem virtutem illam significare (fol. 68a).

El párrafo correspondiente al versículo sexto se encuentra en los fols. $77 \mathrm{a}-77 \mathrm{~b}$ de la edición de 1555. Falta en el apéndice el sintagma hebreo נפשי לאדני, aunque está comentado; sí figura en la edición de 1555. Salvo el primer párrafo de enlace, ambos comentarios latinos son idénticos. Los manuscritos castellanos coinciden prácticamente, excepto en la traducción de Est autem hoc genus schematis (fol. 77b), más literal en VJ (fol. 101a): «Es este género de figura» que en Coimbra (fol. 74a): «este género de figura». El hebreo de Coimbra, como es habitual, aparece también transcrito.

El comentario al versículo séptimo del apéndice falta en la edición de 1555 y, en consecuencia, en los dos manuscritos castellanos. La cita que da de Jerónimo no es tal, sino traducción casi literal del hebreo. Aunque la palabra comentada es פדות, figura también קוה, que debería haber sido incluida en el comentario al versículo quinto, en lugar de פדה.

\section{CONCLUSIONES}

Con estas notas esperamos haber desentrañado, al menos en parte, algunos de los problemas que presenta el comentario de Cipriano de la Huerga al Salmo 130:

1. En la edición de Alcalá de 1555 este autor se sirvió de su edición de Lovaina de 1550.

2. La remodeló estilísticamente 'e incorporó al texto el apéndice con lemas en hebreo que figuraba en la edición de 1550. Al incorporar el apéndice, siguió el mismo procedimiento que había utilizado con el resto de la edición, modificándolo con variantes estilísticas e incluso ampliándolo.

3. La traducción castellana, que es prácticamente la misma en los dos manuscritos que conservamos, fue hecha sobre la edición de 1555 .

4. Aun presentando los dos manuscritos la misma traducción, la copia de Coimbra - que podría parecer más auténtica por llevar la firma del traductor; Bernardino de Mendoça, en la dedicatoria al Duque de Alba- es menos exacta que la copia VJ.

\section{RESUMEN}

Los autores tratan de aclarar algunos de los problemas que suscitan las do ediciones latinas del comentario de Cipriano de la Huerga al Salmo CXXX, y su relación con los dos ejemplares que se conservan en traducción castellana del siglo XVI. Concluyen que la edición latína de 1555 remodela e incluso amplía la de 1550, incorpora al texto del comentario el apéndice de lemas hebreos. La traducción castellana se realizó a partir de la edición de 1555 , y el ejemplar del Instituto «Valencia de Don Juan» es más fiel que el de Coimbra.

\section{SUMMARY}

The authors try to unravel some of the problems arisen by the two Latin edition of Cipriano de la Huerga's commentary on Psalm CXXX and their relationship with the two copies of the Spanish 16th century translation. They conclude that the 1555 Latin edition remoulds and even enlarges that of 1550 , by incorporating the Hebrew appendix into the text of the commentary. The Spanish transhtion was made from faithful to the original than the one of Coimbra. 